\title{
Hypothesis: the aplastic crisis of hereditary spherocytosis is due to a single transmissible agent
}

\author{
PHILIP P MORTIMER* \\ From the Laboratory of Infectious Diseases, National Institute of Allergy and Infectious Diseases, National \\ Institutes of Health, Bethesda, MD 20205 USA
}

SUMmARY Aplastic crisis in sickle cell anaemia has been associated with infection by a serum parvovirus-like virus (SPLV). Reports of outbreaks of these crises in hereditary spherocytosis (HS) were investigated to see if the data were consistent with a single agent such as SPLV being their cause. The age distribution of the cases and the pattern of spread were compatible with an infectious aetiology. The symptoms and duration of the cases, and the intervals between them, were sufficiently uniform to indicate that they were caused wholly or predominantly by a single agent with an incubation period of about nine days. There were close similarities between these illnesses and recognised cases of SPLV infection. It is concluded that SPLV is probably the main cause of aplastic crisis in HS.

Pattison $e t a l^{1}$ and Sergeant $e t a l^{2}$ have recently shown that the aplastic crisis of sickle cell anaemia (SCA) is associated with infection by a $20-23 \mathrm{~nm}$ parvovirus-like particle (serum parvovirus-like virus, SPLV). ${ }^{3}$ They noted the epidemic nature of the crises and the absence of recurrences, and these features led them to suggest that SPLV might be their principal cause. Aplastic crises can arise in any form of haemolytic anaemia, and have occurred with SPLV infection in two families with hereditary spherocytosis (HS), ${ }^{45}$ in a case of pyruvate kinase deficiency and in a case of thalassaemia. ${ }^{6}$

The gene that determines HS is usually expressed in several members of an affected family, and aplastic crises often happen concurrently or successively in siblings and other relatives. There have been many reports of these family outbreaks, especially from the era before HS was routinely treated in early childhood by splenectomy, which apparently prevents crises occurring. In this study, papers reporting aplastic crises in kinships with HS were analysed to see whether the descriptions were compatible with one infectious agent being the cause of these incidents.

*Present Address: PHLS Virus Reference Laboratory, Central Public Health Laboratory, London NW9 5HT.

Accepted for publication 29 November 1982.

\section{Method}

Between 1935 and 1964, 16 papers describing family outbreaks of aplastic crisis in HS were published in which the intervals between the onset of symptoms in the index and the other cases were recorded. $^{7-22}$ Also noted from these papers, and from a further paper describing another outbreak, ${ }^{23}$ were the age and sex of the patients, their relationship to the index cases, their initial symptoms and the occurrence of fever, and the intervals from onset of illness to the reappearance of reticulocytes in the peripheral blood.

\section{Results}

The most frequently observed intervals between the onset of illness in the index and subsequent cases of aplastic crisis were eight days (4 cases) and nine days ( 5 cases). Of the 29 cases arising within 16 days, 22 $(76 \%)$ occurred $9 \pm 3$ days after an index case (Fig.

Relationship of secondary cases of aplastic crisis in hereditary spherocytosis to the index case

\begin{tabular}{lr}
\hline Relationship to index case & $n$ \\
\hline Sibling & 27 \\
Cousin & 5 \\
Parent & 5 \\
Grandparent & 1 \\
Uncle & 1 \\
\hline
\end{tabular}




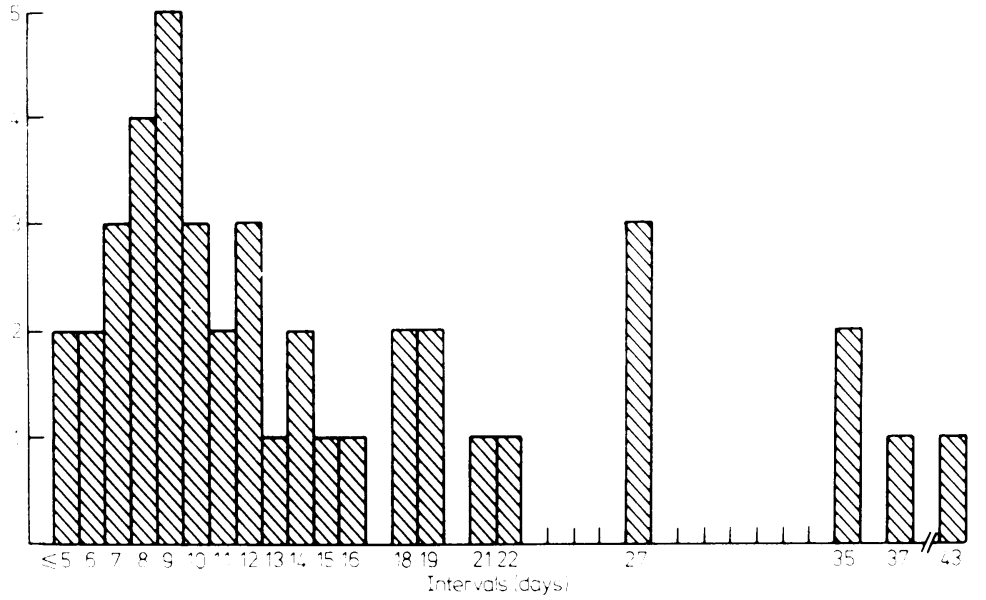

Fig. 1 Intervals between onset of simptoms in index cases and onset in secondary cases during outbreaks of aplastic crisis in families with $H S$.

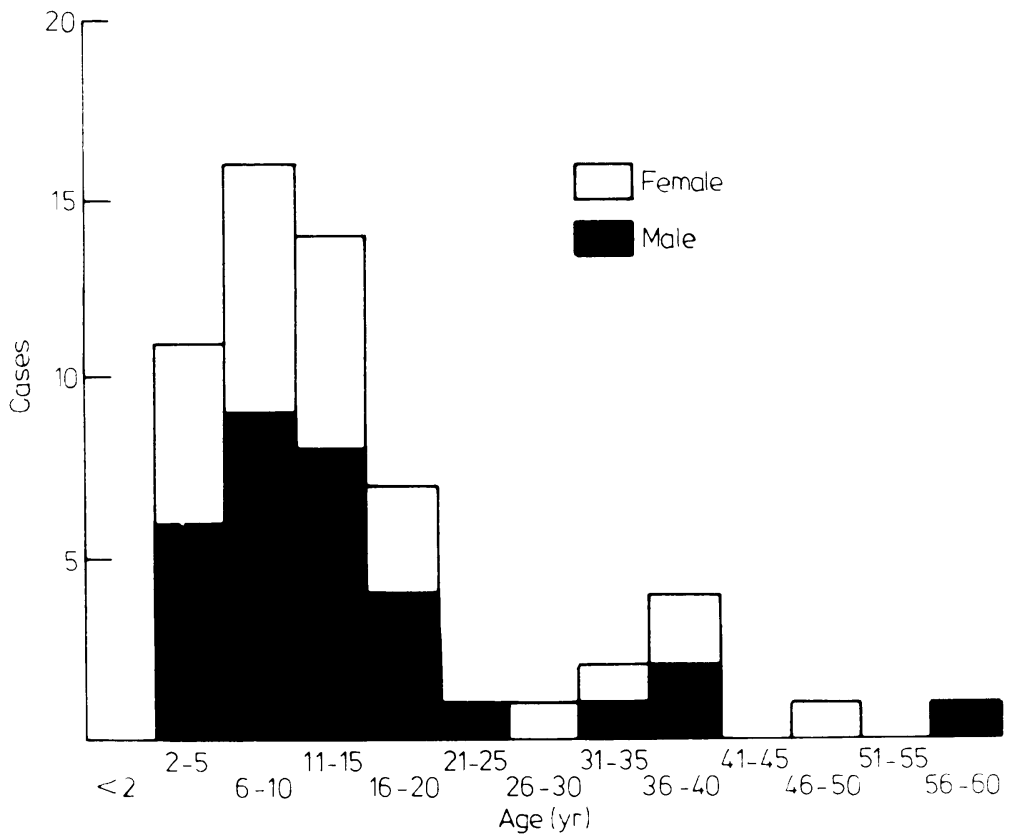

Fig. 2 Age and sex of patients in outbreaks of aplastic crisis affecting families with $H S$.

1). Four other cases occurred after an 18-19 day interval and three after a 27 -day interval. Thirtytwo of 58 patients $(55 \%)$ were male (Fig. 2). None was under $2 \mathrm{yr}$ of age, but $41(71 \%)$, including all the 19 index cases, were under $16 \mathrm{yr}$. The spread was mostly to siblings, but a few adults were secondarily affected (Table 1).

Of the presenting complaints five, in addition to fever, were common: headache, malaise/fatiguc. Ф nausea/vomiting, abdominal pain and rigors (Fig. 3). Five other symptoms, cough, sore throat, diarrhoea. earache and rash, were uncommon. The duration of $\frac{O}{\mathbb{D}}$ the crisis, from the onset of symptoms to the beginning of the reticulocyte response, was defined for $30 \stackrel{\square}{\square}$ patients. It varied from 5 to 20 days: in 19 cases $(63 \%)$ it was $11 \pm 1$ days (Fig. 4 ). 


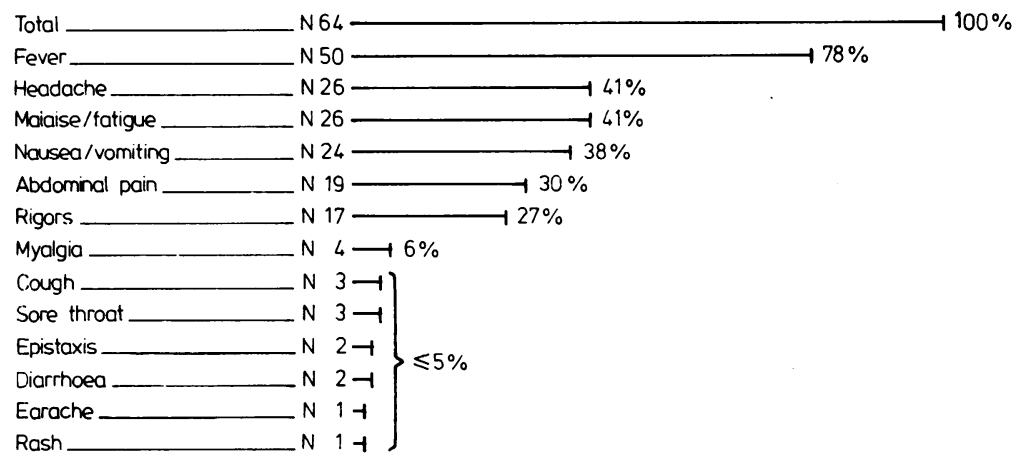

Fig. 3 Presented symptoms and occurrence of fever in $H S$ patients affected during familial outbreaks of aplastic crisis.

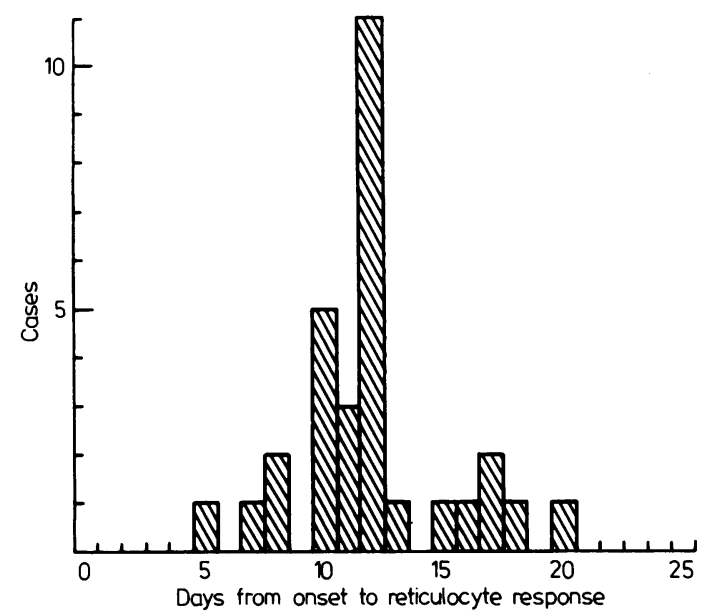

Fig. 4 Interval between onset of symptoms and reappearance of reticulocytes in peripheral blood in $\mathrm{HS}$ patients with aplastic crisis.

\section{Discussion}

In the brief time that a link between SPLV and aplastic crises in haemolytic anaemia has been recognised, the association has proved to be close. Evidence has been found for recent SPLV infection in 34 of 38 crises $(89 \%)$ in a retrospective study of SCA. ${ }^{67}$ This observation prompted a review of published descriptions of outbreaks of aplastic crisis in HS to see whether a single infectious agent such as SPLV could have caused them. Reports of aplastic crises in other haemolytic anaemias were too few to justify including data from them.

There is little doubt that the aplastic crises described in the reports studied were post-infectious and not due, for instance, to a nutritional deficiency, or a toxic effect on already compromised bone mar- row. Children were the first to be affected and adults were largely spared. The crises spread through families in waves rather than arising simultaneously. No cases occurred in infants, implying that there was protection through passively acquired maternal antibody. The presence of similar symptoms in family contacts without HS, alluded to in several of the reports, was further evidence that the crises were caused by one or more transmissible agents and not by a factor peculiar to patients with HS.

Other aspects of the data supported the hypothesis that there is a single infective cause for aplastic crisis in HS. Firstly, there was no history of earlier attacks of aplastic crisis in any of the case reports so that, apparently, no infection had previously caused aplastic crisis in the 64 patients described. Secondly, the interval between the index and the other cases was very commonly $9 \pm 3$ days, and there was a suggestion of further groups of cases arising about 18,27 , and 36 days after the onset of illness in the index case. This implies a consistent incubation period such as a single agent would display. If it is assumed that the onset of symptoms coincides with greatest infectiousness, the incubation period for this agent would be 9 days. Thirdly, the early symptoms of the crises suggested that only a limited number of infectious agents were involved. Several common viral symptoms were largely absent, whereas fever and rigors, headache and abdominal pain were regularly present. It is of interest that these complaints and myalgia (present in four patients) have characterised known SPLV infections unrelated to haemolytic anaemia, ${ }^{24} 25$ and resemble those observed in SPLV-associated crises in SCA. ${ }^{26}$ Fourthly, the termination of the aplastic crises, was regular and invariable. It occurred 10-12 days after onset of symptoms in almost two-thirds of the cases, a similarity in duration of illness that suggests that most cases were due to the same agent. 
The data indicate an infectious aetiology for aplastic crises in HS. Because of the absence of previous crises in the histories of the patients, the defined incubation period and duration of illness, and the repeated occurrence of certain symptoms and absence of others, they are compatible with a single agent being responsible for most or all of the cases. The likenesses between these cases and those of patients with proven SPLV infection imply that this virus was a possible cause; and the facts that recent outbreaks of crises in two families with HS have been linked to SPLV ${ }^{4}$ and that no other agent has been convincingly associated with this syndrome suggest that the link with the virus is close. It is to be hoped that, in future, patients with aplastic crises will be investigated for evidence of infection by this newly-recognised pathogen. Only thus will it be possible to determine how specific is the connection between aplastic crisis and the virus.

I thank Dr RH Purcell for his help in the preparation of this paper.

\section{References}

' Pattison JR, Jones SE, Hodgson J, Davis LR, White JM, Stroud CE, Murtaza L. Parvovirus infections and hypoplastic crises in sickle cell anaemia. Lancet 1981;i:664-5.

${ }^{2}$ Sergeant GR, Topley JM, Mason K, et al. Outbreak of aplastic crises in sickle cell anaemia associated with parvovirus-like agent. Lancet 1981 ;ii:595-7.

${ }^{3}$ Cossart YE, Field AM, Cant B, Widdows D. Parvovirus-like particles in human sera. Lancet 1975;i:71-3.

${ }^{4}$ Kelleher JR, Luban NLC, Mortimer PP, Kamimura T. The human serum "parvovirus": a specific cause of aplastic crisis in hereditary spherocytosis (in press).

${ }^{s}$ Harvey TC, et al. in preparation.

- Anderson MJ. Special article: the emerging story of a human parvovirus-like agent. J Hyg 1982;89:1-9.

${ }^{7}$ Murray-Lyon RM. Familial acholuric jaundice simulating Lederer's anaemia. $\mathrm{Br}$ Med J 1935;1:50-2.

${ }^{8}$ Scott AM. Acholuric jaundice; the serial onset of acute blood crises in an entire family. Lancet 1935 ;ii:872-4.

${ }^{9}$ Dedichen HG. Epidemic occurrence of anemic crises in hemolytic jaundice. Norsk mag. $f$. laegevidensk 1937;98:279-95.

${ }^{10}$ Dameshek W. Familial hemolytic crisis; report of three cases occurring within 10 days. $N$ Engl $J$ Med 1941;224:52-6.
" Horne JL, Lederer H, Kirkpatrick HJR, Leys DG. Familial crises in congenital haemolytic diseases. Lancet 1945;ii:33-6.

${ }^{12}$ Dameshek W, Bloom ML. The events in the hemolytic crisis of hereditary spherocytosis, with particular reference to the reticulocytopenia, pancytopenia and an abnormal splenic mechanism. Blood 1948;3:1381-410.

${ }^{13} \mathrm{Li}$ JG, Voth IG, Osgood EE. Hemolytic crisis in hereditary spherocytosis: study of a family of five with concurrent crises. Ann Intern Med 1950;33:411-7.

14 Marson FG, Meynell MJ, Tabbush H. Familial crisis in acholuric jaundice. Br Med J 1950;ii:760-1.

${ }^{15}$ Ingham WN. A familial crisis in congenital acholuric jaundice. Arch Dis Child 1952;27:34-6.

${ }^{16}$ Battle JD, Jr. Hereditary spherocytosis (congenital hemolytic jaundice): pathogenesis of the "hemolytic" crisis. Am J Med Soc 1952;224:89-92.

17 Esmond WG, Quinn CL, Peters HR. Hereditary spherocytosis in a Negro family; report of 3 cases. Am J Dis Child 1955;90:407-10.

18 Bethe K, Debatin F, Sauthoff R. Aplastische Krise bei konstitutionellen haemolytischen Ikterus gleichzeitige Erkrankung dreier Geschwister im Zusammenhang mit einer Gruppe Infektion. Deutsch Med Wochenschr 1955;80:1358.

${ }^{19}$ Moorhouse JA, Mathewson FAL. Familial haemolytic anaemia: concurrent crises in 3 members of a family. Can Med Assoc $J$ 1956;75:133-5.

${ }^{20}$ Denny WF, Bird RM, DuVal MK. Hereditary spherocytosis; is the duration of the aplasia influenced by splenectomy? Arch Intern Med 1958;101:894-8.

${ }^{21}$ Greig HBW, Metz J, Bradlow BA, Theron JJ, Morris RW. The familial crisis in hereditary spherocytosis: report of 5 cases. $S$ Afr J Med Soc 1958;23:17-32.

${ }^{22}$ Bouroncle BA. Familial crisis in hereditary spherocytosis. $J \mathrm{Am}$ Med Wom Assoc 1964;19:1045-54.

${ }^{23}$ Owren PA. Congenital hemolytic jaundice. The pathogenesis of the "hemolytic crisis". Blood 1948;3:231-48.

${ }^{24}$ Paver WK, Clarke SKR. Cumparison of human fecal and serum parvo-like viruses. J Clin Microbiol 1976;4:67-70.

${ }^{25}$ Shneerson JM, Mortimer PP, Vandervelde EM. Febrile illness due to a parvovirus. Br Med J 1980;ii: 1580 .

${ }^{26}$ Anderson MJ, Davis LR, Hodgson J, et al. Occurrence of infection with a parvovirus-like agent in children with sickle cell anaemia during a two-year period. J Clin Pathol 1982;35:744-9.

${ }^{27}$ Anderson MJ, Davis LR, Jones SE, Pattison JR. The development and use of an antibody capture radioimmunoassay for specific IgM to a human parvovirus-like agent. $J$ Hyg 1982;88:309-24.

Requests for reprints to: Dr PP Mortimer, PHLS Virus Reference Laboratory, Central Public Health Laboratory, Colindale Avenue, London NW9 5HT, England. 